\title{
In Vitro Anthelmintic Efficacy of Fractions from Plumbago zeylanica $L$ (Family- Plumbaginnaceae) Root Extract
}

\author{
Yohannes Weldemariam Getahun ${ }^{1,}$, Afework Mulugeta Bezabh ${ }^{2}$ \\ ${ }^{1}$ Department of Chemistry, Adigrat University, Adigrat, Tigray, Ethiopia \\ ${ }^{2}$ Department of Public Health, Mekelle University, Mekelle, Tigray, Ethiopia
}

Email address:

jonygsfusw@gmail.com (Y. Weldemariam), afework.mulugeta@gmail.com (A. Mulugeta)

\section{To cite this article:}

Yohannes Weldemariam Getahun, Afework Mulugeta Bezabh. In Vitro Anthelmintic Efficacy of Fractions from Plumbago zeylanica L (Family- Plumbaginnaceae) Root Extract. American Journal of Life Sciences. Vol. 3, No. 3, 2015, pp. 134-142.

doi: $10.11648 /$ j.ajls.20150303.12

\begin{abstract}
Unlike synthetic drugs plants have different phytochemical constituents which can act collectively by which helminthes cannot resist them or there could be active constituent(s) in the plant with superior potency. The aim of this study was to investigate the anthelmintic activity of both crude and fractions of Plumbago zeylanica root extract for the purpose of finding long lasting and potent medicinal plant due to significant implications of helminthes in developing countries like Ethiopia. And where traditional medicine is wide spread and of immediate alternative. In the assay, chloroform crude extracts recorded less paralysis and death time than ethanolic crude extracts. Then crude extract was subjected to column chromatography from which nine pure compounds were isolated. In addition, the isolated compounds were higher in their anthelmintic activity than crude extracts at almost all concentrations. Both crude and fractions paralyse and kill the worms with less time than that of the positive control and even less than 10 fold especially at low concentrations in case of chloroform extracts. The findings here on anthelmintic activity of the root at lower concentrations are significant and for the first time. If in vivo data are included the plant can be used as long lasting drug for helminthes.
\end{abstract}

Keywords: Plumbago Zeylanica L, In Vitro Test, Anthelmintic Activity, Extraction, Fractionation

\section{Introduction}

In addition to infectious diseases parasitic worms are another alarm. They cause substantial privation and diminutive growth in animals and man. There are conditions that excides malaria and tuberculosis. Massive drug administration to control human helminthes can minimize but then it leads to emergence of anthelmintic resistance $[1,2]$. When anthelmintic drug is administered sequentially, it eliminates susceptible helminthes without affecting for parasites that are resistant. The resistant parasites in turn pass their resistant genes on to the next generation of worms [3].The majority of diseases caused by helminthes are persistent, weakening nature; and probably cause more morbidity and greater economic and social deprivation among humans and animals than any single group of parasites [4].Therefore, unless drugs especially those synthetic origin are modified or substituted by plant origin drugs with the same or higher potency, drug resistance will be unmanageable. Especially in developing countries like Ethiopia the issue is even more critical.

\subsection{Chemistry of Plumbago zeylanica $L$}

The plant has demonstrated promising bio activity for its wide range chemical constituents.

One investigation done on a real parts of Plumbago zelanica L. $95 \%$ ethanol extract confirmed the presence of seven compounds with the aid of various chromatographic and spectroscopic techniques. According to the study the one triterpenoid (compound 1) was new while compounds 2, 4-7 were obtained from this genus for the first time. Their structures together with their names are displayed (Fig. 1) below. 


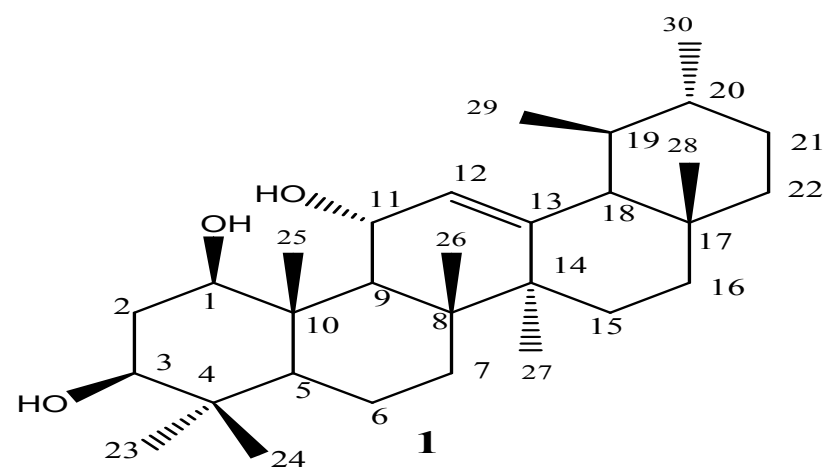<smiles>C[C@H]1CC(=O)c2c(O)cccc2[C@@H]1O</smiles>

3<smiles>CC12C=CC(=O)CC1C1CCC(=O)C1CC2</smiles><smiles>C=CC(C)(C)c1[nH]c2ccccc2c1C=C1NC(=O)[C@H](C)NC1=O</smiles><smiles>Cc1nccc2c1[nH]c1ccccc12</smiles><smiles>CCCC(C)(C)[C@@H](C)[C@H](C)/C=C/[C@@H](C)C(C)C</smiles><smiles>CC1C=C[C@@H](O)[C@]2(O)C[C@H](O)CCC12C</smiles><smiles>CCC</smiles>

6<smiles>CC(=O)OCC(NC(=O)C(Cc1ccccc1)NC(=O)c1ccccc1)c1ccccc1</smiles>

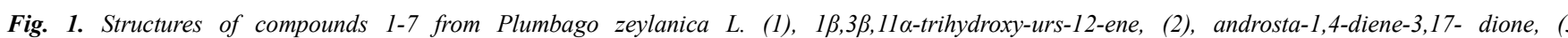
isoshinznolone, (4), neoechinulin A, (5), harman, (6), ergostadiene-3 $\beta, 5 \alpha, 6 \beta$-triol and (7), $N$-(N'-benzoyl-S-phenylalaninyl)-Sphenylalaninol [5].

Phytochemical analysis of crude extracts showed the presence of alkaloids, phenols and flavonoids [6, 7]. In addition the presence of tannins and saponins was detected from methanolic root extracts. The root was found to contain the naphthoquinone plumbagin, composed naphtha quinones, like 3-biplumbagin, chloroplumbagin, chitranone and elliptone; the coumarin sseselin, 5-methoxyseselin, suberosin and xanthyletin. Among all these compounds plumbagin (5hydroxy-2-methyl-1,4- naphthoquinone, ( $\left(\begin{array}{llll}C_{11} & H_{8} & \mathrm{O}_{3}\end{array}\right)$ reported to be the major ingredient with $1 \%$ in the whole plant, but with higher percentages in the root. The stem brings only a trace and the leaves bring no plumbagin
[8].Plumbagin in general is found in different plant families including Plumbaginaceae, Droseraceae, Ancestrocladaceae and Dioncophyllaceae. Plumbagin is also present along with a series of other structurally related naphthoquinones [9]. From fractionation of areal parts of Plumbago zeylanica L.A in bioassay guided system $\beta$-sitosterol, $ß$-sitosteryl-3ßglucopyranoside-6 '-O-palmitate, lupenone, lupe-ol acetate, plumbagin, and trilinolein was revealed to be isolated [10].

On the other hand, phytochemical investigation on the leaf; alkaloids, glycoside, reducing sugars, simple phenolics, tannins, Lignin, saponins and flavonoids gave positive results[11]. 
In a search for larvacidal activity one study found $\beta$ sitosterol (17-(5-Ethyl-6-methylheptan-2-yl)-10,13-dimethyl$2,3,4,7,8,9,11,12,14,15,16,17$ dodecahydro-1H cyclopenta [a]phenanthren-3-ol) and plumbagin. The study had utilized column chromatography and1D, 2D NMR to find out these compounds [12]. Also another journal intended at evaluating the anti-inflammatory and cytotoxic effects of extract from Plumbago zeylanica found out beta-sitosterol and gugultetrol-18-ferrulate with the help of silica gel column

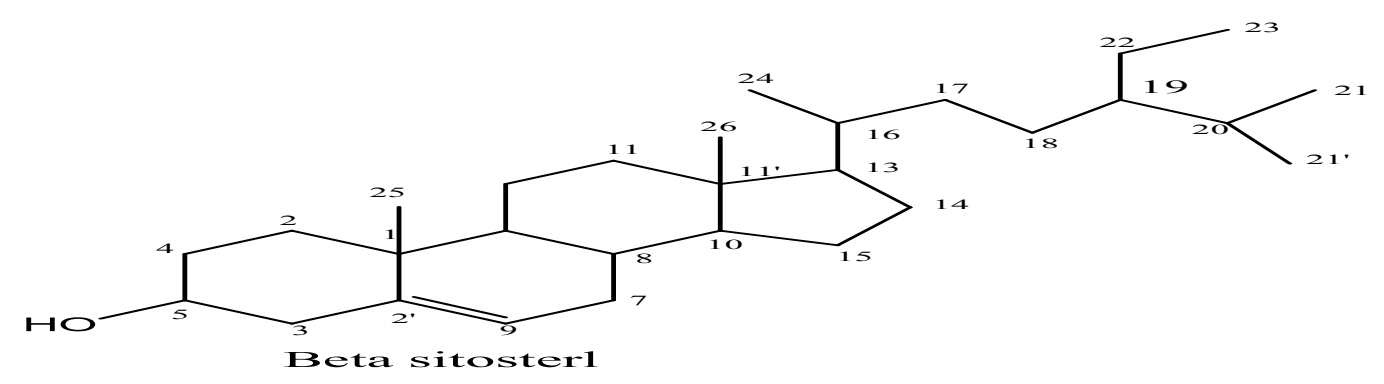<smiles>CCCCCCCCCCC=CCCC(O)C(O)C(O)COC(=O)C=Cc1ccc(OC)c(O)c1</smiles>

Guggultetrol-18-ferrulate

Fig. 2. Beta sitosterl and guggltetrol-18-ferrulate.

On one study, Plumbagozeylanica L extracts were run in TLC with chloroform/methanol solvent system (8:2) and yield four bands. Plumbagin alone was detected by spraying with $10 \%(\mathrm{w} / \mathrm{v})$ ethanolic solution of $\mathrm{KOH}$, followed by heating at $100^{\circ} \mathrm{C}$ until the red color appeared to the first band. Further it was confirmed by comparison of ${ }^{1} \mathrm{H},{ }^{13} \mathrm{C}$ NMR and GC-MS spectral data with values described in the literature for plumbagin[14].

A flavonoid compound (Fig. 3) known as 2-(2, 4Dihydroxy-phenyl)-3, 6, 8-trihydroxy-chromen-4-one (yield: $0.082 \%$ on dry weight) was also detected in another study by spraying with ferric sulphate reagent. To confirm this, elucidation was done by means of UV, IR ${ }^{1} \mathrm{H}$ - and ${ }^{13} \mathrm{C}-\mathrm{NMR}$ spectroscopic methods[15].<smiles>O=c1c(O)c(-c2ccc(O)cc2O)oc2c(O)cc(O)cc12</smiles>

2-(2, 4-Dihydroxy-phenyl)-3, 6, 8-trihydroxy-chromen-4-one

Fig. 3. 2-(2, 4-Dihydroxy-phenyl)-3, 6, 8-trihydroxy-chromen-4-one.

\subsection{Biological Activity of Plumbago zeylanica}

\subsubsection{Antimicrobial Activity}

A journal paper from Kollihills, south India revealed that chromatography, high performance liquid chromatography (HPLC) and proton and carbon nuclear magnetic resonance spectroscopy analysis (1H and 13C NMR), Infra red and mass spectroscopy. In the same study prelimenary phytochemical screening of dichloromethane extract of Plumbago zeylanica root confirmed the presence of terpenoids, flavanoids and absence of steroids, carbohydrate, alkaloids and tannins [13]. 
extract with an MIC value of $150 \mathrm{mg} / \mathrm{ml}$ [17].

A comparative study of the root versus callus of plumbago zeylanica $L$. in various test microorganisms revealed that the root and the callus as well have antimicrobial activity (in vitro). But the root has found to have highest activity. It was found that the root extract show zone of inhibition against all microorganism whereas callus extract show maximum zone of inhibition against the $S$. aureusand M.luteus.MIC of root extract against $S$. aureus and $M$. luteuswas 1250 and $2500 \mu \mathrm{g} / \mathrm{ml}$ respectively. Whereas the MIC of callus extract against these microorganisms was $5000 \mu \mathrm{g} / \mathrm{ml}$ as determined by turbidity method[18].

Plumbagozeylanica L. extracts (ethyl acetate fraction) also showed bactericidal activity against Helicobacter pylori. Four fold MIC concentrations of the extracts killed all the population with in the 4 hrs of incubation while the two fold concentration showed the similar effect in 8 hrs. Plumbagozeylanica $L$. demonstrated promising in vitro efficacy against multidrug resistant bacteria and it is ranked in a group of plants with over all broad spectrum of antimicrobial activity [19].

\subsubsection{Antioxidant Activity}

Ethanolic root extracts Plumbago zeylanica $L$ and isolated flavonoid (2-(2, 4-Dihydroxy-phenyl)-3, 6, 8- trihydroxychromen-4-one) were screened for antioxidant activity by free radical scavenging and superoxide radical scavenging assays. The plant root extracts showed significant antioxidant activity as compared to standard flavonoid (Quercetin). The antioxidant activity by DPPH was $96 \mu \mathrm{g} / \mathrm{ml}$ and by NBT it was $4.6 \mu \mathrm{g} / \mathrm{ml}$ which was greater than that of standard (Quercetin) $45 \mu \mathrm{g} / \mathrm{ml}$ by DPPH and $10 \mu \mathrm{g} / \mathrm{ml}$ by NBT assay[15].

Including Plumbago zeylanicaL. four Indian medicinal plants were assessed for their antioxidant capacity by ferric thiocyanate (FTC) assay and compared with thiobarbituric acid (TBA) method. Plumbago zeylanicaL. showed highest antioxidant potential according to FTC assay. Further, the radical-scavenging activity of the extracts was measured as decolourizing activity followed by the trapping of the unpaired electron of DPPH. The percentage decrease of 1, 1diphenyl-2-picryl hydrazyl radical (DPPH) standard solution was recorded significant for Plumbagozeylanica L. (73.41\%). It was the second compared to the other plants.

Methanolic extract of leaves of Plumbagozeylanica L. was also checked for their total antioxidant activity. At all the studied concentrations, the plant extract showed slightly higher activity than $\alpha$-tocopherol[20].

In one study, the in vitro antioxidant activity of ethanolic extract of roots of Plumbagozeylanica was investigated by DPPH free radical scavenging, nitric oxide scavenging and superoxide scavenging methods at dose of $100-1000 \mu \mathrm{g} / \mathrm{mL}$. The ethanol extract showed good antioxidant activity in these methods. The maximum activity was found in DPPH free radical scavenging model. The antioxidant activity was dose dependent.

There are various invitro antioxidant test methods like reducing power and nitric oxide scavenging activity and in vivo models like tissue GSH levels and lipid peroxidation. Ethanol extracts of leaves of Plumbago zeylanica L exhibited significant in vitro and in vivo antioxidant activity in those assays[21].

\subsubsection{Anthelmintic Activity}

Leaf extracts $P$. zeylanicaL. were tested for anthelimntic activity against adult earth-worms (Pheretimaposthuma) at 25, 50 and $100 \mathrm{mg} / \mathrm{ml}$ concentrations. All of the three concentrations of extracts of Plumbago zeylanica L. showed significant dose dependent anthelmintic property. Results clearly indicated that $100 \mathrm{mg} / \mathrm{ml}$ concentration of the extract has the highest potency as an anthelmintic (took least time to cause paralysis and death of the worms) compared to standard drug piperazine citrate and albendazole [20].

Anthelmintic activity of the root as confirmed in another study done at various concentrations $(5,10,15,20 \mathrm{mg} / \mathrm{ml})$ reveal that methanolic extract of Plumbago zeylenica showed higher activity as compared to water extract. Methanolic extracts kill the worms in $81 \pm 1.5 \mathrm{~min}$ at $20 \mathrm{mg} / \mathrm{ml}$ compared to standard piperazine citrate which kill the worms in $36 \pm 0.9$ at same concentration. Anthelmintic activity was observed by gradually increasing the dose of extract [22].

Plants such as plumbago zeylanica with all this phyto constituents and bioactivity should be assessed for different assays In different methods and at different places. As drug resistance is really a matter, finding long lasting plant derived drug will be the immediate measurement. The goal of this study was to test the anthelmintic activity of Plumbago zeylanica root extract and fractions. There are few reports especially on the anthelmintic property of root extract of the plant and this paper will be the first to report on the anthelmintic activity of fractions and that of crude extract at low concentrations.

\section{Experimental}

\subsection{Materials}

\subsubsection{Chemicals and Solvents}

Sodium chloride, siligcagel, sodium sulphate anhydrous $\left(\mathrm{Na}_{2} \mathrm{SO}_{4}\right)$,distilled water, cyclo hexane, diethyl ether, chloroform, dichloromethane, carbontetrachloride, ethyl acetate, acetone, $\mathrm{n}$ - hexane, methanol, ethanol and Tween- 80 . The entire chemicals used were analytical grade obtained from the chemical store of Mekelle University.

\subsubsection{Instruments and Equipments}

Ultra violet - visible light, rotary evaporator (laborata 4000, Heithbad bath, 230,50/60 Hz), electrical shaker, soxhlet extractor set up, separatory funnel,Thinlayer chromatography plate(glass and aluminum support), chamber, glass column chromatography, vacuum pump, oven, fridge and desikator were the equipments utilized.

\subsubsection{Test Organisms}

Earthworm: Pheretima posthuma 


\subsection{Methods}

\subsubsection{Material Collection}

Plumbago zeylanica L. roots fresh, were obtained in the month Aug - Sep/ 2013. Voucher specimen was deposited at the National Herbarium of Addis Ababa University with voucher specimen number B (003).

\subsubsection{Extraction}

Shade-dried roots of Plumbago zeylanica $L$ were crushed in to powder using mortar and pestle. The dried and powdered root material $(156 \mathrm{~g})$ was extracted in $800 \mathrm{ml}$ chloroform for $36 \mathrm{~h}$ at once using soxhlet extraction method. Root powder of Plumbago zeylanica (238g) was also extracted by maceration in 1.5 liters of ethanol for three day on an electrical shaker (shake speed 220 at room temprature). Both the extracts were filtered using What man No1 filter paper and the filtrate was concentrated by rotary evaporator at room temperature and further with vacuum pump $[18,23$, 24].

\subsubsection{Anthelmintic Activity}

\section{(i). Earthworm's Collection and Authentication}

Healthy adult earthworm (Pheretimaposthuma) were collected from water logged area of the soil and identified in Department of Biology of Mekelle University. Earthworms in moist soil were washed with normal saline and used for the study. The earthworms of $4-7 \mathrm{~cm}$ in length and $0.1-0.2 \mathrm{~cm}$ in width were used for all the experimental protocol due to its anatomical and physiological resemblance with the intestinal roundworm parasites of human beings. Because of easy availability, earthworms have been used extensively for the preliminary in vitro evaluation of anthelmintic compounds [2].

\section{(ii). Preparation of Crude Extracts and Isolated Fractions for Bioactivitytest}

Exactly $0.2 \mathrm{~g}$ of crude chloroform extract was dissolved in $2 \mathrm{ml}$ chloroform to get $100 \mathrm{mg} / \mathrm{ml}$ concentration. This was then serially diluted to obtain $50 \mathrm{mg} / \mathrm{ml}, 25 \mathrm{mg} / \mathrm{ml}, 10 \mathrm{mg} / \mathrm{ml}$ and $5 \mathrm{mg} / \mathrm{ml}$ concentrations as shown in (Fig. 4) below.

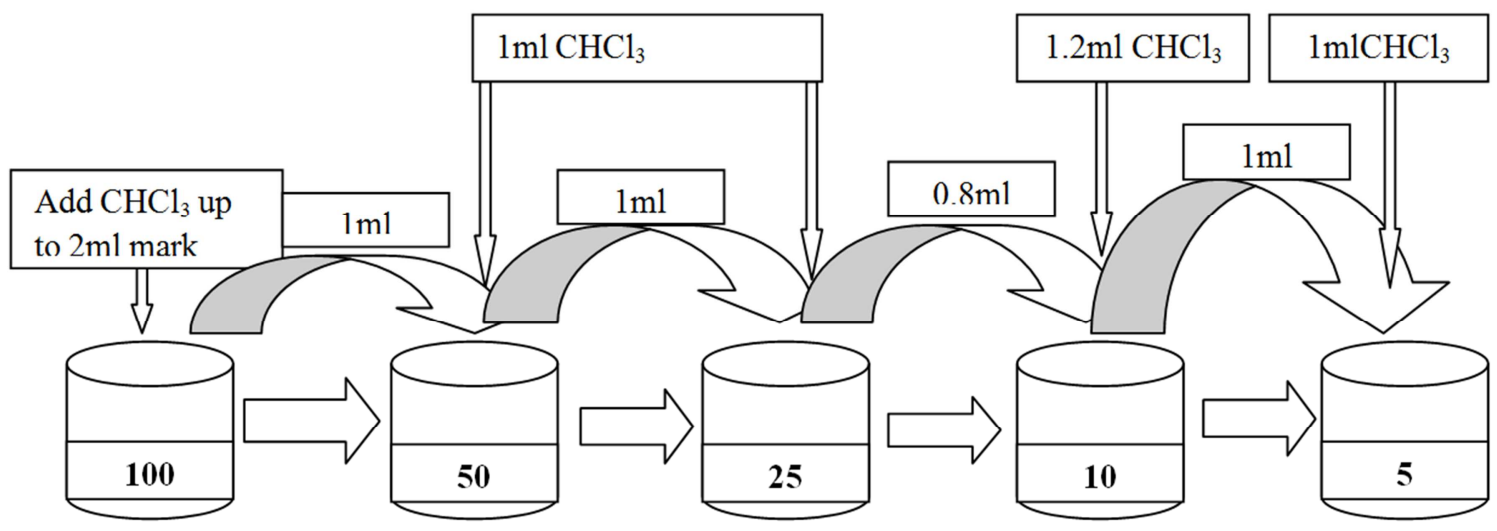

Fig. 4. Serial dilution procedure.

This procedure was repeated for ethanol extracts using ethanol as a solvent for dilution. In preparation of samples for anthelmintic test $0.2 \mathrm{~g}$ of both chloroform and ethanol extracts was taken separately and serially diluted by the same procedure explained above, but the dilution was done with $2 \%$ Tween 20 suspended in normal saline solution [25]. Similar dilution procedure was applied for the fractions corresponding to their lower quantity.

\section{(ii). Anthelmintic Investigation of the Crude Chloroform and Ethanol Extracts}

The anthelmintic activity was done following the method described in (Lakshmanan, B. et al, 2011)[26]with modest modification.

The worms were divided into three groups containing sixearth worms in each group. All the prototypes were dissolved in minimum quantity of $2 \% \mathrm{v} / \mathrm{v}$ Tween 80 and the volume was adjusted to $10 \mathrm{ml}$ with normal saline for making the concentration of $1,2,3,4,5,10,25,50$ and $100 \mathrm{mg} / \mathrm{ml}$ for chloroform crude extracts and 5, 10, 25, 50 and $100 \mathrm{mg} / \mathrm{ml}$ for ethanol extracts. All the prototypes and the standard drug were freshly prepared before commencement of the experiments. All the earthworms were washed in normal saline solution before they were released into $10 \mathrm{ml}$ of respective formulation as follows, vehicle $(2 \% \mathrm{v} / \mathrm{v}$ Tween 80 in normal saline), extracts and piperazine citrate at (1, 2, 3, 4, $5,10,25,50$ and $100 \mathrm{mg} / \mathrm{ml})$. The anthelmintic activity was determined in six observations. Six worms in about the same size per petridish were used. They were observed for their spontaneous motility and evoked responses. Observations were made for the time taken to paralysis and death of individual worms. Paralysis was said to occur when the worms do not revive even in normal saline with ice. Death was concluded when the worms lost their motility in cold water followed with fading away of their body color [2].

\section{(iii). Anthelmintic Investigation of Fractions}

Similar procedure was followed as for the crude extracts. The only differences were $3-5$ earth worms were included in a group and final dilutions were fixed to 5 milliliters attributed to their yield.

\subsubsection{Statistical Analysis}

Calculations were carried out in triplicate with their mean 
values and standard deviations by formula in the Microsoft excell.

\section{Result and Discussion}

\subsection{Yield of Plumbago zeylanica Root Powder}

Soxhletextaction of the root with chloroform and maceration with ethanol gave $0.82 \% \mathrm{w} / \mathrm{w}$ and $3.31 \% \mathrm{w} / \mathrm{w}$ of the powder extracted respectively.

\subsection{Anthelmintic Activity}

\subsubsection{Chloroform Crude Extracts}

The anthelmintic activity of chloroform crude extracts was significant. They paralyzed and killed the earthworms by less than half the time taken for piperazine citrate to paralyze and kill the worms (Table 1). At lower concentrations, the time taken to paralyze and kill the earthworm was less than 10 fold to that of the positive control. For example, the paralysis and death time for chloroform crude extracts was 540, 552 and 900, 960 seconds at 2 and $1 \mathrm{mg} / \mathrm{ml}$ respectively. Whereas, for piperazine citrate they were 12000, 16200 and 30000, 35400 seconds at the same concentrations. Even if chloroform is not as polar as ethanol, methanol or water some of the bioactive compounds such as alkaloids, flavonoids and quinones are extractable within it. The bioactivity of alkaloids on central nervous system also works for worms as seen in the inhibition of chloroform extract [2].

Table 1. Anthelimntic activity of crude chloroform extract of Plumbago zeylanica L against Adult earthworms Pheretima posthuma.

\begin{tabular}{lll|l}
\hline \multirow{2}{*}{ Treatment group } & Concentration & \multicolumn{2}{l}{ Time taken (seconds) } \\
\cline { 2 - 4 } & mg/ml & Paralysis & Death \\
\hline & 100 & $120 \pm 21$ & $192 \pm 26$ \\
& 50 & $150 \pm 22$ & $240 \pm 33$ \\
Chloroform & 25 & $192 \pm 19$ & $312 \pm 24$ \\
extract & 10 & $282 \pm 20$ & $378 \pm 59$ \\
& 5 & $360 \pm 26$ & $408 \pm 81$ \\
& 4 & $468 \pm 33$ & $480 \pm 90$ \\
& 3 & $510 \pm 25$ & $540 \pm 64$ \\
& 2 & $540 \pm 16$ & $552 \pm 82$ \\
& 1 & $900 \pm 29$ & $960 \pm 100$ \\
& 100 & $300 \pm 27$ & $1080 \pm 93$ \\
& 50 & $540 \pm 35$ & $1800 \pm 96$ \\
& 25 & $960 \pm 28$ & $3240 \pm 135$ \\
& 10 & $1380 \pm 49$ & $3740 \pm 125$ \\
\hline $5 i p e r a z i n e ~ c i t r a t e$ & 5 & $2700 \pm 56$ & $4380 \pm 180$ \\
& 4 & $3600 \pm 68$ & $4680 \pm 200$ \\
& 3 & $4920 \pm 45$ & $5700 \pm 250$ \\
& 2 & $12000 \pm 67$ & $16200 \pm 320$ \\
& 1 & $30000 \pm 36$ & $35400 \pm 402$ \\
\hline
\end{tabular}

Results on this biological study were reported as mean \pm Standard deviation. $\mathrm{n}=6$ in each group.

\subsubsection{Ethanolic Crude Extracts}

Ethanolic extracts showed highest activity than the positive control but less than the chloroform extracts. Earth worms die at 600 and 960 seconds in ethanol extracts at 100 and $50 \mathrm{mg} / \mathrm{ml}$. While, the positive control killed the worms at 1080 and 1800 seconds at the same concentration. However, as the concentration decreased worms were paralyzed and killed by pirerazine citrate at relatively shorter time than the ethanolic extracts. Journal papers published in this assay suggested the reason for the potency of their plants is mainly relied to the presence of alkaloids, tannin and flavonoids[1,27,28,29,30].The significant anthelmntic activity of ethanolic extracts in the present study can be argued in the same way.

Table 2. Anthelmintic activity of crude ethanolic extract of Plumbago zeylanica L. against adult earthworms Pheretimaposthuma.

\begin{tabular}{llll}
\hline \multirow{2}{*}{ Treatment group } & $\begin{array}{l}\text { Concentration } \\
\text { mg/ml }\end{array}$ & \multicolumn{2}{l}{ Time taken (seconds) } \\
\cline { 3 - 4 } & 100 & Paralysis & Death \\
\hline \multirow{5}{*}{ Ethanol extract } & 50 & $270 \pm 23$ & $600 \pm 32$ \\
& 25 & $300 \pm 30$ & $960 \pm 23$ \\
& 10 & $900 \pm 43$ & $2580 \pm 95$ \\
& 5 & $3000 \pm 51$ & $4800 \pm 67$ \\
Piperazine citrate & 100 & $3600 \pm 57$ & $6300 \pm 26$ \\
& 50 & $300 \pm 42$ & $1080 \pm 67$ \\
& 10 & $540 \pm 46$ & $1800 \pm 55$ \\
& 5 & $960 \pm 29$ & $3240 \pm 65$ \\
\hline
\end{tabular}

Results on this biological study were reported as mean \pm Standard deviation. $\mathrm{n}=6$ in each group.

In the literature it was discussed the anthlmintic activity of the methanolic extracts of PlumbagozeylanicaL. leafs against adult earthworms Pheretimaposthuma. Compared to present study anthlmintic activity of the leaf is much less. Leaf extracts paralyzed and killed the worms at 26.833 and 33 minutes respectively [20]. Both chloroform and ethanolic extracts paralyzed and kill worms in less than 11 minutes at the same concentration $(100 \mathrm{mg} / \mathrm{ml})$.On another study, anthelimintic activity of metanolic extract of the root paralyse and kill the worms in $33 \pm 1.6$ and $81 \pm 1.5 \mathrm{~min}$ at $20 \mathrm{mg} / \mathrm{ml}$ while water extracts paralyse and kill the worms in $190 \pm 1.2228 \pm 1.2 \mathrm{~min}$ at same concentrations. In comparison to this study, the present findings were even less than to that of approximately4.7, $6.3 \mathrm{~min}$ paralysis and death time recorded by chloroform crude extracts [22].

\subsubsection{Anthelmintic Activity of Fractions}

\section{(i). Chloroform Crude Extract Fractions}

Isolated compounds of the chloroform crude extract were tested for anthelmintic activity at different concentrations. With respect to chloroform crude extract at parallel concentrations all the fractions show higher activity, but Pure $\mathrm{F}_{1}$ and Pure $\mathrm{F}_{5}$ at $1 \mathrm{mg} / \mathrm{ml}$. The time of paralysis and death of adult earth worms Pheretima posthuma decreased with increase in concentration (Table 3 ) 
Table 3. Anthelimntic activity of nhexane - ethyl acetate $\left(F_{1}-F_{7}\right)$ and chloroform $\left(F_{8}\right)$ fractions of chloroform crud extracts of Pumbago zeylanicaL. against adult earthworms Pheretima posthuma.

\begin{tabular}{|c|c|c|c|}
\hline \multirow{2}{*}{$\begin{array}{l}\text { Treatment } \\
\text { groups }\end{array}$} & \multirow{2}{*}{$\begin{array}{l}\text { Concentrations } \\
(\mathrm{mg} / \mathrm{ml})\end{array}$} & \multicolumn{2}{|c|}{ Time taken (seconds) } \\
\hline & & Paralysis & Death \\
\hline \multirow{3}{*}{ Pure $F_{1}$} & 3 & $4010 \pm 155$ & $5155 \pm 166$ \\
\hline & 2 & $4560 \pm 213$ & $6060 \pm 184$ \\
\hline & 1 & $5040 \pm 301$ & $7320 \pm 55$ \\
\hline \multirow{3}{*}{ Mixture $\mathrm{F}_{2}$} & 3 & $550 \pm 40$ & $780 \pm 21$ \\
\hline & 2 & $600 \pm 23$ & $840 \pm 34$ \\
\hline & 1 & $710 \pm 32$ & $811 \pm 38$ \\
\hline \multirow{3}{*}{ Pure $F_{3}$} & 3 & $48 \pm 11$ & $60 \pm 14$ \\
\hline & 2 & $71 \pm 10$ & $120 \pm 14$ \\
\hline & 1 & $82 \pm 9$ & $120 \pm 17$ \\
\hline \multirow{3}{*}{ Mixture $\mathrm{F}_{4} \mathrm{M}$} & 3 & $188 \pm 20$ & $200 \pm 26$ \\
\hline & 2 & $248 \pm 21$ & $278 \pm 25$ \\
\hline & 1 & $262 \pm 12$ & $278 \pm 15$ \\
\hline \multirow{3}{*}{ Pure $\mathrm{F}_{5} \mathrm{P}$} & 3 & $400 \pm 19$ & $440 \pm 33$ \\
\hline & 2 & $650 \pm 25$ & $760 \pm 23$ \\
\hline & 1 & $840 \pm 98$ & $1020 \pm 123$ \\
\hline \multirow{3}{*}{ Pure $\mathrm{F}_{6} \mathrm{P}$} & 3 & $200 \pm 16$ & $215 \pm 17$ \\
\hline & 2 & $194 \pm 32$ & $220 \pm 37$ \\
\hline & 1 & $198 \pm 32$ & $210 \pm 37$ \\
\hline \multirow{3}{*}{ Pure $\mathrm{F}_{7} \mathrm{P}$} & 3 & $240 \pm 19$ & $277 \pm 22$ \\
\hline & 2 & $260 \pm 12$ & $308 \pm 43$ \\
\hline & 1 & $300 \pm 24$ & $550 \pm 23$ \\
\hline \multirow{3}{*}{ Pure $\mathrm{F}_{8} \mathrm{P}$} & 3 & $90 \pm 16$ & $120 \pm 21$ \\
\hline & 2 & $203 \pm 18$ & $250 \pm 33$ \\
\hline & 1 & $300 \pm 28$ & $310 \pm 43$ \\
\hline
\end{tabular}

Results on this biological study were reported as mean \pm Standard deviation. $\mathrm{n}=3-5$ in each group.

\section{(ii). Ethanolic Crude Extract Fractions}

The data from the Table 4.below shows that the isolated compounds have superior anthelmintic activity than analogous crude extracts. They take less time to paralyse and kill the worms compared to positive control. Bioactive plant chemo constituents are commonly extractable with ethanol. These phytochemicals are still the reason behind the significantly higher activity of these fractions too. In agreement to this study plants extracted with ethanol were found to be potent anthelminthes. Higher inhibition was recorded than the standard drug used in the assay. Ethanolic crude extracts of Saracaindica leaves for instance were superior in their anthelmntic activity than the methanol extracts and piperazine citrate a positive control in the assay within the same study [27]. Extracts from Symplocosracemosa were also more active in those groups in which ethanol as extracting medium compare to pet ether extracts and similar with chloroform extracts [31]. Whereas,crude ethanol extracts of Pterospermumacerifolium Linn. were found to exceed in their activity against Pheretimaposthuma (worm) in contrast to pet ether, ethyl acetate, chloroform extracts of the bark [28].
Table 4. Athelmintic activity of $n$ hexane - ethyl acetate $\left(F_{A}-F_{C}\right)$ fractions of ethanolic crude extracts of Plumbago zeylanica L. against adult earthworms Pheretimaposthuma.

\begin{tabular}{llll}
\hline $\begin{array}{l}\text { Treatment } \\
\text { groups }\end{array}$ & Concentrations $(\mathbf{m g} / \mathbf{m l})$ & \multicolumn{2}{c}{ Time taken (seconds) } \\
\cline { 3 - 4 } & 3 & Paralysis & Death \\
\hline \multirow{2}{*}{ Pure $\mathrm{F}_{\mathrm{A}} \mathrm{P}$} & 2 & $300 \pm 14$ & $395 \pm 36$ \\
& 1 & $300 \pm 29$ & $407 \pm 45$ \\
& 3 & $360 \pm 44$ & $420 \pm 54$ \\
Mixture $\mathrm{F}_{\mathrm{B}}$ & 2 & $472 \pm 18$ & $480 \pm 26$ \\
& 1 & $578 \pm 19$ & $596 \pm 13$ \\
& 3 & $600 \pm 28$ & $689 \pm 18$ \\
Pure $\mathrm{F}_{\mathrm{C}} \mathrm{P}$ & 2 & $520 \pm 21$ & $880 \pm 98$ \\
& 1 & $1200 \pm 114$ & $1320 \pm 196$ \\
& & $1405 \pm 114$ & $1560 \pm 196$ \\
\hline
\end{tabular}

Results on this biological study were reported as mean \pm standard deviation. $\mathrm{n}=3-5$ in each group.

\section{Conclusion}

Chloroform and ethanolic root extracts of have observed to be inhibiter to earth worms Pheretima posthuma. At all the concentrations used they paralyzed and killed the worms by considerably shorter time than the standard piperazine citrate. Higher potency was recorded in chloroform extracts compared to ethanolic extracts. It could be concluded that Plumbago zeylanica $L$. root have anthelmintic efficacy. Extractable individual compounds which can be converted to anthelmintic drug can be obtained such as the nine pure compounds isolated here. The assays done here are in vitro which require further data from in vivo studies to be valuable. Though nine pure compounds are isolated here they lack spectroscopic analysis to identify the actual chemical constituents and to relate the data with their structures and functional groups. People in the area use Plumbago zeylanica mostly for ailments where by their source or cause is not known for them. Such as, allergy and sun stroke. "Aftuh" in its local name means "a solution". This study could be used confidentially to show the anthelmintic use of the plant. However, for its high toxicity we cannot suggest the people to administer it as traditional drug.

\section{Acknowledgements}

This research was initiated immediately after promising data was obtained from phytochemical screening, antioxidant and antimicrobial activity of the plant published before. Several researchers and lab assistances were participated and those mentioned here are acknowledged for their overt contribution. So, we are grateful to Miss Adeline Lectard (guest lecturer from France) for her supervision and technical assistance during the work, Hadush Ashebrom, technical assistance of Organic Chemistry Research Laboratory, Department of Chemistry, Mekelle University. Esmail Abdu, technical assistance of undergraduate Organic Chemistry Laboratory, Alem Halefom, technical assistance of Analytical Chemistry Laboratory, Department of Chemistry, Mekelle University. Haftom Hayle, technical assistance of Veterinary Laboratory The Department of Veterinary Medicine, Mekelle 
University, The Department of Chemistry, Veterinary Medicine, Biology, Mekelle University.

\section{References}

[1] S. Vidyadhar, M. Saidulu, T. K. Gopal, D. Chamundeeswari, U. Rao and D. Banji, "In vitro anthelmintic activity of the whole plant of EnicostemmaLittorale by using various Extracts," Int. J. App. Biol. Pharmace. Tech., I(3), 1119-1126, 2010.

[2] P. Tiwari, B. Kumar, M. Kumar, M. Kaur, J. Debnath and P. Sharma, "ComparativeAnthelmintic Activity of Aqueous and Ethanolic Stem Extract of TinosporaCordifolia,” Int. J. Drug Dev. Res., 3 (1), 70-83, 2011.

[3] A. Kumar, K. Lakshman, K. N. Jayaveera, R. Nandeesh, B. Mano and D. Ranganayakulu, "Comparative In vitro Anthelmintic Activity of Three Plants From the Amaranthaceae Family," Arch. Biol. Sci. Belgrade, 62(1), 185-189, 2010.

[4] M. M. Suleiman, M. Mamman, O.Y. Aliu and O. J. Ajanusi, "Anthelmintic Activity of the Crude Methanol Extract of Xylopiaaethiopica Against Nippostrongylusbrasiliensis in Rats," Veterinary Arhiv, 75(6), 487-495, 2005.

[5] X. Huang, M. Tan, Q. Wu, Y. Chen and H. Wang, "Chemical constituents from the aerial parts of Plumbago zeylanicaL," Chinese J. Pharmace. Sci., 17(2), $144-147,2008$.

[6] D. A. Dhal and S. K. Markandeya, "Antimicrobial and Phytochemical Screening of Plumbagozeylanica Linn. (Plumbaginaceae) Leaf," J. Exp. Sci., 2(3), 04-06, 2011.

[7] I. Ahmad, and F. Aquil, "In vitro efficacy of bioactive extracts of 15 medicinal plants against esbetal-producing multidrugresistant enteric bacteria," Microbiol. Res.,Chem Abst, 162(3), 264-275, 2007.

[8] I. Sharma, D. Gusain and V. P. Dixit, "Hypolipidaemicand antiatherosclerotic effectsof plumbagin in rats," Indian J. Physiol Pharmacol., 35(1), 10-14, 1991.

[9] F. Aqil, M. Zahin and I. Ahmed, "Antimutagenic activity of methanolic extracts of four ayurvedic medical plant,".Indian J.Exp. Biol., 5, 668-672, 2008.

[10] A. T. Nguyen, H. Malonne and P. Duez, "Cytotoxic constituents from Plumbago zeylanica. Fitoterapia," J.Org. Chem., Chem. Abst., 75(5), 500-504, 2004.

[11] R. Tyagi and E. Menghani, "Phytochemical screening of Plumbago zeylanica: A potent Herb," Int. J. Pharma. Sci. Res., 5(03), 71-72, 2014.

[12] B. Maniafu, L. Wilber, O. I. Ndiege, C. C. Wanjala and A. T. Akenga, Larvicidalactivity of extracts from three plumbago species against Anopheles Gambiae,".Mem. Inst Oswaldo Cruz. Rio de Janeiro, 104(6), 813-817, 2009.

[13] K. D. Arunachalam, P. Velmurugan and R. B. Raja, "Antiinflammatory and cytotoxic effects of extract from Plumbago zeylanica,” Afr. J. Microbiol. Res., 4(12), 1239-1245, 2010.

[14] R. Jeyachandran, A. Mahesh, L. Cindrella, S. Sudhakar and K. Pazhanichamy, "Antibacterial activity of plumbagin and root extracts of PlumbagoZeylanica L.," ACTA BIOLOGICA CRACOVIENSIA Series Botanica, Chem. Abst, 51(1), 17-22, 2009.
[15] H. S. Nile, and N. C. Khobragade, "Antioxidant activity and flavonoid derivatives of PlumbagoZylanica," J. Nat. Prod., $130-133,2010$

[16] R. S. Paiva, R. M. Figueiredo, V. T. Aragão and C. A. M. Kaplan, "Antimicrobial activity in vitro of plumbagin isolated from plumbago species," .Mem Inst Oswaldo Cruz, 98(7), 959-961, 2003.

[17] S. M. Rahman, and M. N. Anwar, "Antimicrobial activity of crude extract obtainedfrom the root of Plumbago zeylanica," Bangladesh J. Micro Biol., 24(1), 73-75, 2007.

[18] V. Mittal and K. S. Sharma, "An In vitro antimicrobial activity of callus and root extracts of Plumbago ZeylanicaLinn. In Various Test Microorganism,".Int. J.Pharmac. Sci. Rev. Res., 5(2), 1-4, 2010.

[19] Y. C. Wang, and L. T. Huang, "Anti-helicobacter pylori activity of Plumbago Zeylanica L.," FEMS Immu. Med. Microbiol., Chem Abst, 43(3), 407-412, 2005.

[20] M. S. Kataki, N. D. Sharma, S. Kuma, S. R. Yadav, A. Rajkumari "Antibacterial activity, in vitro antioxidant activity and anthelmintic activity of methanolic extract of Plumbagozeylanica L. leaves," J. Pharmac. Res., 3(12), 29082912, 2010

[21] M. Khan, K. K. S. Kori, P. Kumar, R. S. Setty and S. V. Rajendra, "Antioxidant and nephroprotective activity of leaves of Plumbago zeylanica Linn.," Indian J. Pharm., Chem. Abst, 583 131, 2006.

[22] H. P. Desai, M. D. Kapadia, and A. R. Kharat, "Evaluation of anthelmintic activity of Plumbago Zeylanica Linn.," Int. J. Pharmac. Sci. Res., 3(11), 4281-4284, 2012.

[23] J. P. Dzoyem, J. G. Tangmouo, D. Lonts, F. X. Etoa and P. J. Lohoue, "In vitro antifungal activity of extract and plumbagin from the stem bark of Diospyroscrassiflora Hiern(Ebenaceae),"Phytothe. Res., 21(7), 671-674, 2007.

[24] A. J. Aladesanmi, E. O. Iwalewa, A. C. Adebajo, E. O. Akinkunmi, B. J. Taiwo, F. O. Olorunmola, and A. Lamikanra, "Antimicrobial and antioxidant activities of some Nigerian medicinal plants," Afr. J. Trad. CAM, 4(2), 173 $184,2007$.

[25] A. Shahverdi, M. Iranshahi, R. Mirjani, H. Jamalifar, G. Amin and A. Shafiee, "Bioassay- guided isolation and identification of an antibacterial compound from Ferula persica var. Persica roots,” DARU, 13(1), $17-19,2005$.

[26] B. Lakshmanan, M. P. Mazumder, D. Sasmal, S. Ganguly, and S. S. Jena, "In vitro anthelmintic activity of some 1substituted imidazole derivatives," Acta Parasi., 2(1), 1-5, 2011.

[27] N. Sarojini, A. S. Manjari, and C. C. Kanti, "Phytochemical screening and anthelminticactivity study of saracaindica leaves extracts,” Int. Res. J. Pharm., 2(5), 194-197, 2011.

[28] S. Parida, J. V. Patro, S. U. Mishra, L. Mohapatra and S. Sannigrahi, "Anthelmintic potential of crude extracts and its various fractions of different parts ofPterospermumacerifolium Linn," Int. J. of Pharmac. Sci. Rev \& Res., 1(1), 107-111, 2010.

[29] G. R. Mali and A. Mehta, "A Review on Anthelmintic plants," Nat. Prod. Radi., 7(5): 466- 475, 2008. 
[30] H. Roy, A. Chakraborty, S. Bhanja, S. B. Nayak, R. S. Mishra and P. Ellaiah, "Preliminary phytochemical investigation and anthelmintic activity of Acanthospermum Hispidum DC," J. Pharmac. Sci. Tech., 2(5), 217-221, 2010.
[31] N. Rao, B. Bhavya, K. Pavani, A. Swapna and C. Prasoona, "Anthelmintic activity of Symplocos Racemosa," Int. J. Pharm. Biol. Sci., 1(3), 198-230, 2011. 